\title{
The Release of Enzymes and Proteins from Baker's Yeast Disrupted by a Agitator Bead Mill ${ }^{\dagger}$
}

\author{
Kanji Matsumoto and Haruhiko Ohya \\ Dept. of Material Science and Chemical Engineering, \\ Faculty of Engineering \\ Yokohama National University* \\ Sadam Ito \\ Mitsubishi Heavy Industries Co., Ltd.** \\ Makio Naito \\ $R \& D$ Center, Hosokawa Micron Corp.***
}

\begin{abstract}
Baker's yeast suspended in pure water was disintegrated by the agitator bead mill using glass beads having a diameter of 0.5 to $2.0 \mathrm{~mm}$. ADH (alcohol dehydrogenase) was released faster than protein and G-6-PDH (glucose-6-phosphate dehydrogenase), and a concept of the selective release of enzyme was defined. The final weight of the protein released and the activities of enzymes, the release rate constant for protein and $A D H$, and the release selectivity between the protein and $A D H$ were dependent on the bead size, the weight of beads and the agitation speed. The optimum condition for release existed for each operation parameter. The electrical conductivity of the yeast slurry had good correlation with the amount of G-6-PDH and protein released. This result indicated that the degree of release for these substances could be estimated from the measurement of electric conductivity.
\end{abstract}

\section{Introduction}

The release of intracellular materials (such as enzymes) after cells have been disrupted or crushed is an important downstream process that can be effected either chemically or mechanically ${ }^{1,2)}$. Mass production schemes frequently depend on the available mechanical facilities, such as high-pressure homogenizers ${ }^{3)}$ and bead mills ${ }^{4}$, the characteristics of which have been previously compared ${ }^{3,4)}$.

The high-speed agitator bead mill, which is widely used to disrupt bacteria, quickly disintegrates cells into fine pieces. Disintegrating cells into fine pieces is a good method for releasing a sufficient quantity of intracellular materials. At the same time, however, disintegration

\footnotetext{
* 156, Tokiwadai, Hodogaya-ku, Yokohama 240 TEL. 045 (335) 1451

** 1-1-1, Wadasaki-cho, Hyogo-ku, Kobe 652 TEL. 078 (672) 3111

*** No.9, Shoudai Tajika 1-chome, Hirakata, Osaka 573 TEL. 0720 (55) 2220

This report was originally printed in $J$. Soc. Powder Technology, Japan, 26, 424-429 (1989) in Japanese, before being translated into English with the permission of the editorial committee of the Soc. Powder Technology, Japan.
}

tends to cause various problems in post-treatment processes, such as the separation of solids from liquids in the disrupted bacteria materials ${ }^{7)}$, which increases the amount of impurities present.

Overtreating is therefore unnecessary to destroy cytoplasms if the target materials can be sufficiently released by a milder disintegration process that selectively disrupts cell walls. For materials that cannot be sufficiently released unless the cells are thoroughly disrupted, their subsequent separation and purification may be performed more efficiently in a two-stage process. First the cells are mildly disrupted to destroy cell walls selectively, and second, the cells are disrupted thoroughly after releasing and removing the separable materials produced in the first stage.

Intracellular materials such as enzymes and proteins can be selectively released depending on the morphologies and locations of the target materials. The similar concept of chemically disrupting the cells is called "biochemical cell refining" by Asenjo ${ }^{8)}$. For mechanical disruption, the possibility of selectively releasing 
yeast enzymes has been demonstrated using a high-speed agitator bead mill ${ }^{9,10}$ ).

A low-speed bead mill, which disrupts cells at a lower rate than a high-speed bead mill, has the following advantages: continuous cell disruption with a separation of released materials, a lower rate of temperature increase, controlled deactivation of the released enzymes caused by a high shear rate ${ }^{11}$, and low levels of contamination and impurities caused by wear.

In this study, the authors have investigated the release characteristics (i.e., release quantity, release rate and selectivity) of enzymes and proteins that are separated in batches from baker's yeast by a low-speed agitator bead mill, and the effects of the operating parameters (i.e., bead size, bead quantity, and agitation rate) on these characteristics.

\section{Experimental Apparatus and Procedure}

\section{1 Bead mill and beads}

The bead mill used in this study was crusher (Aquamizer AQ 5), equipped with a rotor and six agitation rods ( $15 \mathrm{~mm}$ in diameter) vertically arranged on the same periphery. Each agitation rod was $0.06 \mathrm{~m}$ away from the mill center. The agitation tank was $0.20 \mathrm{~m}$ in diameter and $0.25 \mathrm{~m}$ high. Both the agitation rods and the tank were made of stainless steel (SUS 304).

Three types of beads (glass spheres with a density of $2.48 \times 10^{3} \mathrm{~kg} / \mathrm{cm}^{3}$, Union Co., Ltd.) were used with average diameters of $0.5,1.0$ and $2.0 \mathrm{~mm}$, respectively.

\section{2 Experimental procedure}

Ionized water was added to $0.5 \mathrm{~kg}$ of wet baker's yeast (S. cereviciae, Oriental Yeast Co., Ltd.) to $2 \times 10^{-3} \mathrm{~cm}^{3}$, and the mixture was charged into the agitation tank. As pretreatment, it was agitated at $100 \mathrm{rpm}$, and then agitated at a given speed after a given quantity of the glass beads was added to the tank. A small quantity of a silicon-base defoaming agent was used when the agitation was accompanied by an excessive amount of foaming. The defoaming agent produced no adverse effects on the released yeast. The yeast slurry was kept at approximately $297 \mathrm{~K}$ by circulating cooling water through the jacket surrounding the agitation tank.

The bead mill was stopped periodically to collect the samples (approximately $10^{-5} \mathrm{~m}^{3}$ each). Each sample was then separated centrifugally (operating conditions: 15,000 rpm, 30 min) immediately after it was collected, and the supernatant liquid was removed and analyzed for enzyme activity, water-soluble protein content, $\mathrm{pH}$ level, and electric conductivity. The enzymes analyzed for activity were ADH (alcohol dehydrogenase) and G-6-PDH (glucose6-phosphate dehydrogenase), which were analyzed in accordance with the methods described in the Oriental Yeast Co., Ltd.'s biochemicals catalog (p. 9 and p. 45). The water-soluble proteins were measured according to the Lowry method, with bovine serum albumin as the standard $^{12)}$. The particle size distribution of the disrupted yeast was determined by a Coulter counter (aperture diameter: $30 \mu \mathrm{m}$ ).

\section{Results and Discussion}

3. 1 Rate of release of $\mathrm{ADH}, \mathrm{G}-6-\mathrm{PDH}$ and protein

Figure 1 shows the effects of agitation time on the quantity of released $\mathrm{ADH}, \mathrm{G}-6-\mathrm{PDH}$ and proteins. Most $\mathrm{ADH}$ was released during the

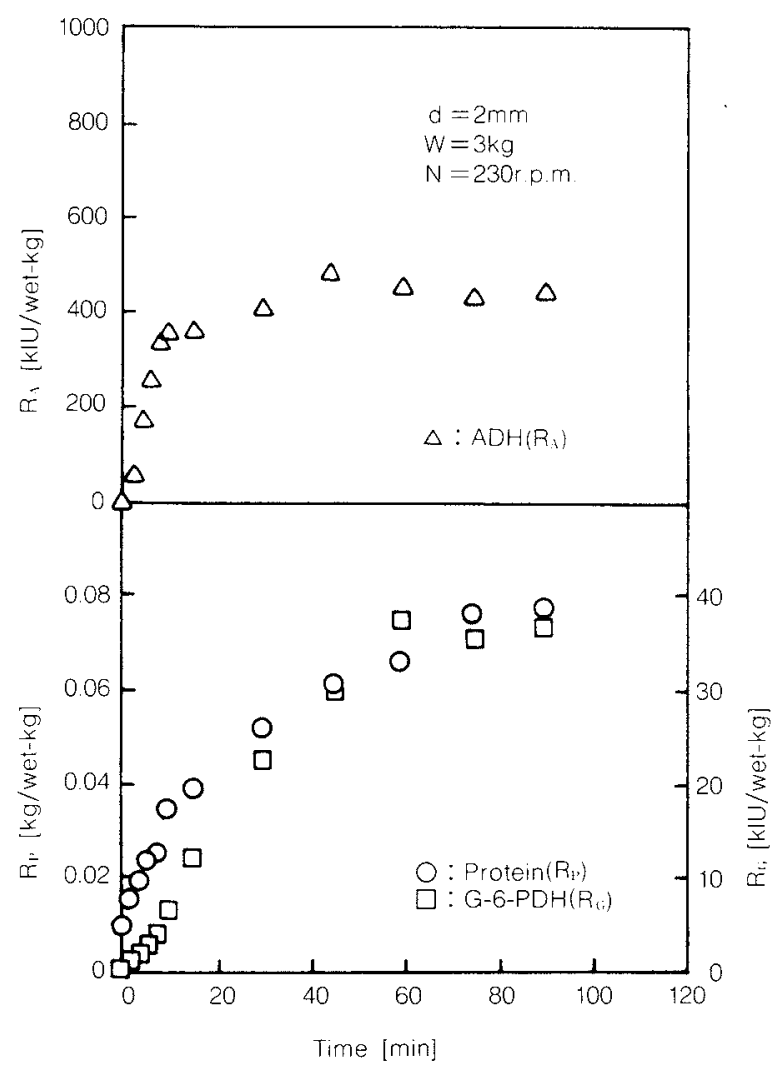

Fig. 1 Rate of release of ADH, G-6-PDH and protein 
intitial stage of agitation, as it is located close to the cell walls ${ }^{13)}$. The quantity of released G-6PDH and proteins, mainly present in cytoplasm, increased with time. The release curves for G-6PDH and proteins are quite similar, and the selectivity characteristics are discussed mainly with respect to $\mathrm{ADH}$ and proteins.

The results shown in Fig. 1 were replotted in Fig. 2 to show the relationship between $R_{m} /$ $\left(R_{m}-R\right)$ and time. As shown, the released quantity of both ADH and proteins correlates fairly well with agitation time according to the equation: ${ }^{14)}$

$$
\ln \left[R_{m i} /\left(R_{m i}-R_{i}\right)\right]=K_{i} t
$$

$i=\mathrm{A}$ (for $\mathrm{ADH}$ ) or $\mathrm{P}$ (for proteins)

where, $R_{m}$ is the maximum released quantity, $K$ is a constant given by the inclination of the curve shown in Fig. 2, and $t$ is the agitation time.

\section{2 Selectivity of enzyme release}

As illustrated schematically in Fig. 3, $R_{\mathrm{A}}$ reaches a constant level in a shorter time than $R_{\mathrm{p}}$. The time at which the sharp increase in $R_{\mathrm{A}}$ stops is defined as $T_{C}$, which corresponds to the release rate of ADH. Figure 4 shows the relationship between $K_{\mathrm{A}}$ and $T_{C}$ under various

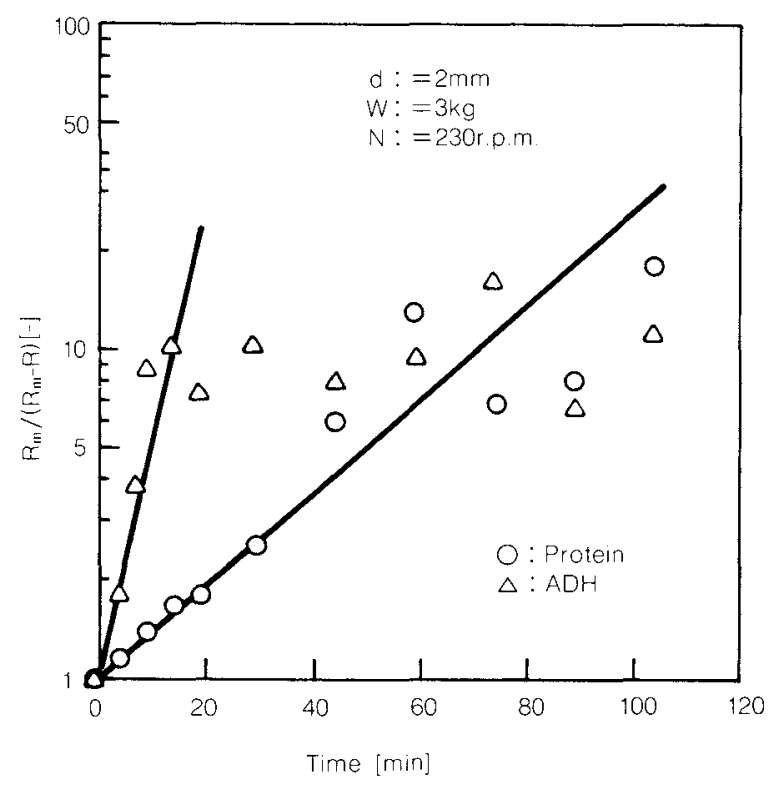

Fig. 2 Plot of $\ln \left[R_{m} /\left(R_{m}-R\right)\right]$ against $t$

conditions and indicates that $K_{\mathrm{A}}$ is almost inversely proportional to $T_{C}$.

Next, the ratios $K_{\mathrm{A}} / K_{\mathrm{P}}$ and $X_{\mathrm{A}} / X_{\mathrm{P}}\left(X_{i}=R_{i}\right.$

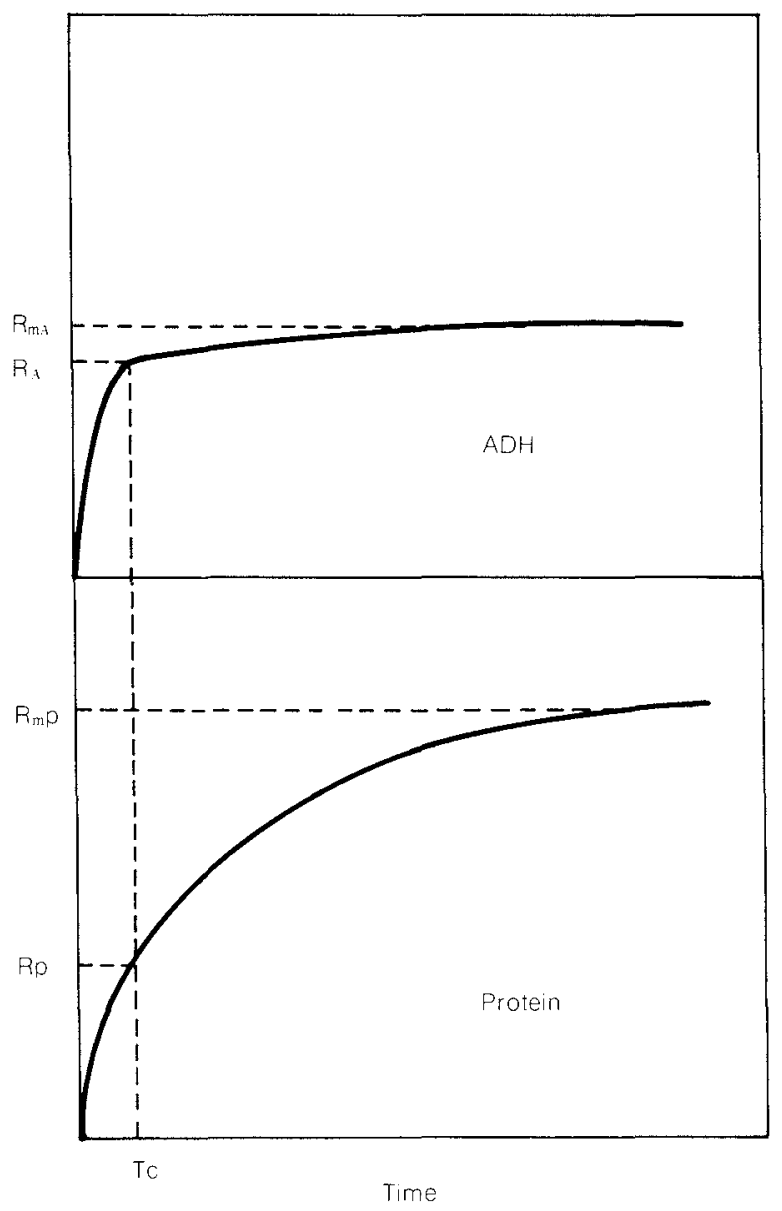

Fig. 3 Definition of a release selectivity between $\mathrm{ADH}$ and protein

at $t=T_{C}\left(R_{m i}\right)$ were introduced as criteria to assess the effects of each operating parameter on the selectivity of enzyme release. $K_{A} / K_{P}$ and $X_{\mathrm{A}} / X_{\mathrm{P}}$ represent the ratio of the release rate constant and the $\mathrm{ADH}$ release rate at $t=$ $T_{C}$ to those of proteins during the initial stage of agitation. A higher ratio indicates a higher selectivity of release.

The effects of each parameter on these selectivity criteria are discussed below. It should be noted, however, that the data was scattered fairly widely, probably as a results of uneven yeast production conditions, experimental conditions, and the conditions under which the yeast was preserved. The results reported herein are the average values for 2 to 4 data items obtained under the same conditions.

\section{3 Bead size}

Table 1 (A) summarizes the effects of bead size (diameter) on the release characteristics of materials separated from yeast when using $3 \mathrm{~kg}$ 
Table 1 Characteristics of substances released from distupted baker's yeast

\begin{tabular}{|c|c|c|c|c|c|c|c|c|}
\hline & & & $\begin{array}{c}R_{m \mathrm{~A}} \\
\left(\frac{\mathrm{KIU}}{\text { wet-kg }}\right)\end{array}$ & $\begin{array}{c}R_{m \mathrm{P}} \\
\left(\frac{\mathrm{kg}}{\text { wet-kg }}\right)\end{array}$ & $\begin{array}{c}K_{\mathrm{A}} \\
\left(\mathrm{min}^{-1}\right)\end{array}$ & $\begin{array}{c}K_{\mathrm{p}} \\
\left(\mathrm{min}^{-1}\right)\end{array}$ & $\begin{array}{c}K_{\mathrm{A}} / K_{\mathrm{P}} \\
(-)\end{array}$ & $\begin{array}{c}X_{\mathrm{A}} / X_{\mathrm{P}} \\
(-)\end{array}$ \\
\hline \multirow{3}{*}{ A } & $d[\mathrm{~mm}]$ & 0.5 & 460 & 0.10 & 5.0 & 1.4 & 3.6 & 2.6 \\
\hline & $W=3 \mathrm{~kg}$ & 1.0 & 660 & 0.12 & 18.3 & 3.3 & 5.5 & 2.6 \\
\hline & ${ }^{\mathrm{I}} N=230 \mathrm{rpm}$ & 2.0 & 480 & 0.08 & 17.0 & 3.5 & 4.9 & 2.0 \\
\hline \multirow{4}{*}{ B } & $W[\mathrm{~kg}]$ & 2.5 & 470 & 0.08 & 14.0 & 2.8 & 5.0 & 1.8 \\
\hline & $d=2 \mathrm{~mm}$ & 3.0 & 480 & 0.08 & 17.0 & 3.5 & 4.9 & 2.0 \\
\hline & ${ }^{[} N=230 \mathrm{rpm}$ & 4.5 & 530 & 0.09 & 21.3 & 4.6 & 4.7 & 1.9 \\
\hline & & 6.0 & 740 & 0.08 & 30.8 & 9.5 & 3.2 & 1.9 \\
\hline \multirow{4}{*}{$\mathrm{C}$} & $N[\mathrm{rpm}]$ & 120 & 600 & 0.08 & 7.6 & 2.0 & 3.8 & 1.9 \\
\hline & $d=2 \mathrm{~mm}$ & 230 & 480 & 0.08 & 17.0 & 3.5 & 4.9 & 2.0 \\
\hline & $\mathrm{W}=3 \mathrm{~kg}$ & 320 & 600 & 0.08 & 23.2 & 4.3 & 5.4 & 2.4 \\
\hline & & 460 & 370 & 0.08 & 13.0 & 5.4 & 2.4 & 1.1 \\
\hline
\end{tabular}

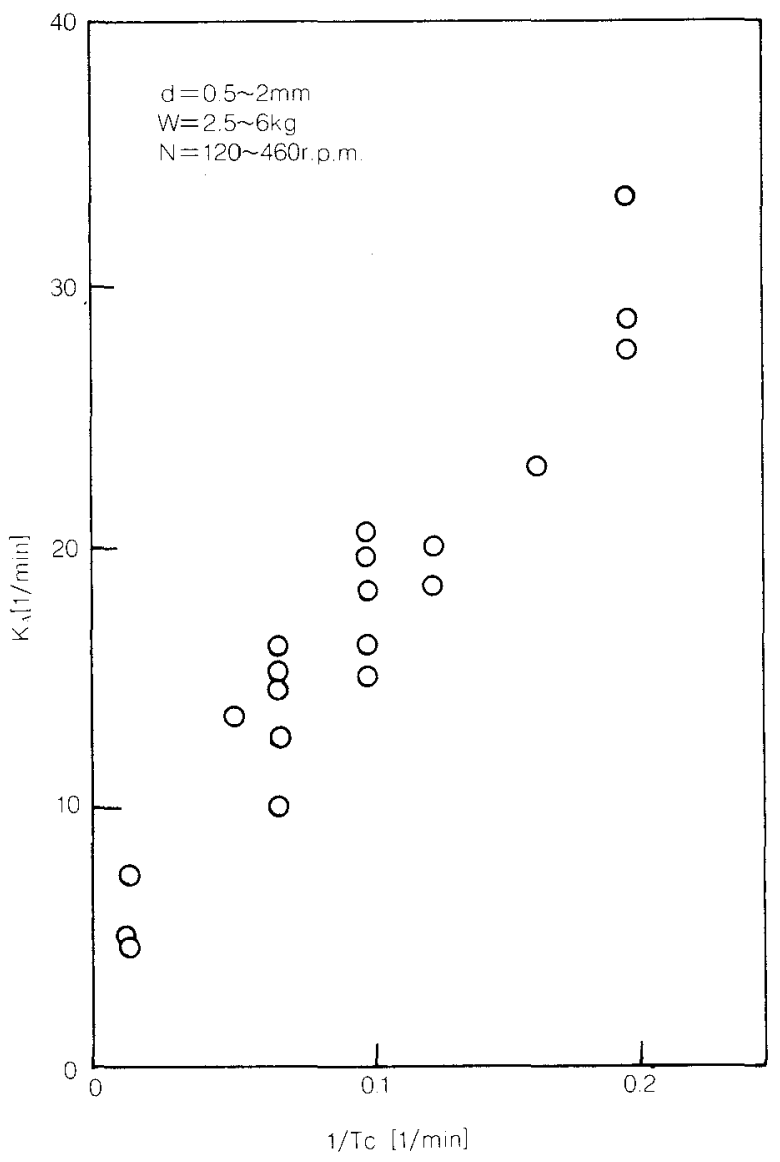

Fig. 4 Relationship between $K_{\mathrm{A}}$ and $I / T_{C}$

of beads and an agitator speed of $230 \mathrm{rpm}$. Both $R_{m \mathrm{~A}}$ and $R_{m \mathrm{P}}$ attained their maximum levels at a bead diameter $(d)$ of $1 \mathrm{~mm}$. Schutte, et al., disrupted yeast with glass beads of $d=$ 0.5 to $1.0 \mathrm{~mm}$ in a horizontal continuous bead mill (Netzsch LME 20), and demonstrated that
$R_{m}$ attains a maximum at $d=1 \mathrm{~mm}$ for the enzymes present near the cell walls and at $d=$ $0.75 \mathrm{~mm}$ for those present in the cytoplasm ${ }^{4)}$. Their results also show optimum bead size for producing a maximum $R_{m}$ value varies depending on the location of the target enzyme in the cell.

The $K_{\mathrm{A}}$ and $K_{\mathrm{P}}$ values agreed with each other when beads of $d=1$ to $2 \mathrm{~mm}$, but the beads of $d=0.5 \mathrm{~mm}$ produced the lowest $K_{\mathrm{A}}$ and $K_{\mathrm{P}}$ values used in this study. Currie, et al., observe that the $K_{\mathrm{P}}$ value increases as bead size diameter decreases from 0.5 to $3 \mathrm{~mm}$ (glass beads for a Netzsch Molinex KE 5 unit) ${ }^{15)}$. Marffy, et al., on the other hand, have tested glass beads of $d=0.1$ to $1 \mathrm{~mm}$ in a Dyno-Mill unit and observed that the $K_{\mathrm{P}}$ value attains a maximum at $d=0.5 \mathrm{~mm}^{9)}$.

As discussed above, the effects of bead size on the $K_{\mathrm{A}}$ and $K_{\mathrm{P}}$ levels vary depending on the type of apparatus used. It is expected that in a closed-type mill, such as a horizontal bead mill, the rate of bead collision necessary for disruption is not decreased much by using small beads because their movement is restricted by the surface of the walls. In an open-type bead mill (such as the apparatus used in this study), on the other hand, lightweight beads are affected more by the flowing liquid, with the result that the rate of bead collision decreases, thus decreasing the $K$ values.

Beads of $d=0.5 \mathrm{~mm}$ produced the highest $K_{\mathrm{A}} / K_{\mathrm{P}}$ ratio, followed by those of $d=2 \mathrm{~mm}$ and then $d=1 \mathrm{~mm}$. The $X_{\mathrm{A}} / X_{\mathrm{P}}$ ratio was almost the same for beads of $d=0.5$ and $1 \mathrm{~mm}$, while 
that for beads of $d=2 \mathrm{~mm}$ was slightly lower.

We therefore conclude that beads of $d=$ $1 \mathrm{~mm}$ produce the optimum release results under the conditions used in this study. However, it was still unknown whether these beads would produce optimum release results under different operating conditions. Therefore the effects of bead quantity and agitation rate on the release characteristics were investigated using beads of $d=2 \mathrm{~mm}$, which are heavy enough to remain unaffected by the flowing liquid.

\section{4 Bead quantity}

Table 1 (B) summarizes the results of the effects of bead quantity $(W)$ on the release characteristics at an agitator speed of $230 \mathrm{rpm}$. A given quantity of beads was added to $2 \times$ $10^{-3} \mathrm{~m}^{3}$ of the slurry containing the yeast, and hence the height of the liquid varied with the quantity of beads. Before agitation, the height of the liquid was approximately $0.11 \mathrm{~m}$ at $W=$ $3 \mathrm{~kg}$ and $0.14 \mathrm{~m}$ at $W=6 \mathrm{~kg}$, which corresponds to the distance of approximately $0.05 \mathrm{~m}$ and $0.02 \mathrm{~m}$ between the bead surface and the liquid surface.

The $R_{m \mathrm{~A}}$ and $R_{m \mathrm{P}}$ values were constant

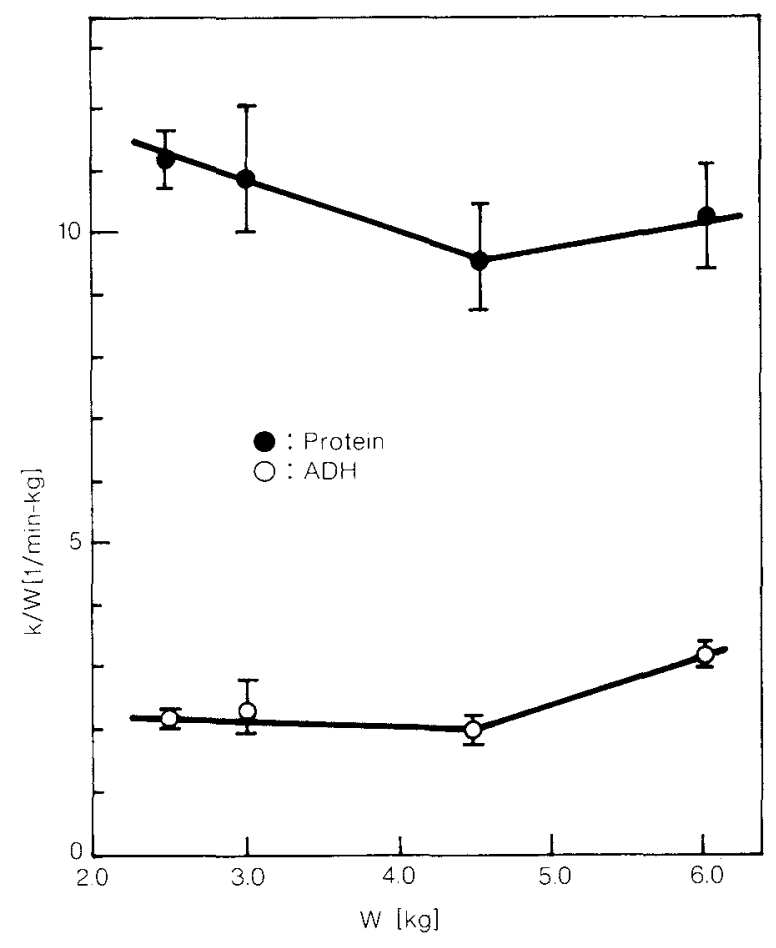

Fig. 5 Effect of the weight of glass beads on the release rate constant of $\mathrm{ADH}$ and protein with respect to bead quantity, except that the $R_{m \text { A }}$ level at $W=6 \mathrm{~kg}$ was slightly higher than the others.

Figure 5 shows the effects of bead quantity $W$ on the $K_{\mathrm{A}} / W$ and $K_{\mathrm{P}} / W$ ratios. As shown, these ratios are almost independent of $W$, except for $K_{\mathrm{P}} / W$ at $W=6 \mathrm{~kg}$; i.e, $K_{\mathrm{A}}$ and $K_{\mathrm{P}}$ are almost proportional to $W$. It was observed that the release rate constant of proteins was almost proportional to $W^{2}$ during the disintegrating of yeast in a vertical bead mill ${ }^{15)}$.

The possible reasons cited for the higher $R_{m \mathrm{~A}}$ and $K_{\mathrm{P}} / W$ values at $W=6 \mathrm{~kg}$ than those at lower $W$ levels were (a) the increased apparent density of those beads in the lower portion of the tank and (b) the changed pattern of movement of the beads that from the increased bead load. The $K_{\mathrm{A}} / K_{\mathrm{P}}$ and $X_{\mathrm{A}} / X_{\mathrm{P}}$ ratios were constant with respect to bead quantity, except for those at $W=6 \mathrm{~kg}$.

\section{5 Agitation speed}

Table 1 (C) summarizes the results on the effects of agitator speed $(N)$ on the release characteristics. As shown, $R_{m \mathrm{~A}}$ changed with $N$, but $R_{m \mathrm{P}}$ was almost independent of $N$. The reasons for the irregular changes in $R_{m \mathrm{~A}}$ are unknown.

Figure 6 shows the effects of agitator speed $N$ on the $K_{\mathrm{A}} / N$ and $K_{\mathrm{P}} / N$ ratios. The $K_{\mathrm{A}} / N$ ratio is almost constant, irrespective of $N$ in a range from 100 to $320 \mathrm{rpm}$, but drops sharply at $N=460 \mathrm{rpm}$. In contrast, the $K_{\mathrm{P}} / N$ ratio decreases gradually with $N$. Therefore, each of the $K_{\mathrm{A}} / K_{\mathrm{P}}$ and $X_{\mathrm{A}} / X_{\mathrm{P}}$ ratios attains a maxi-

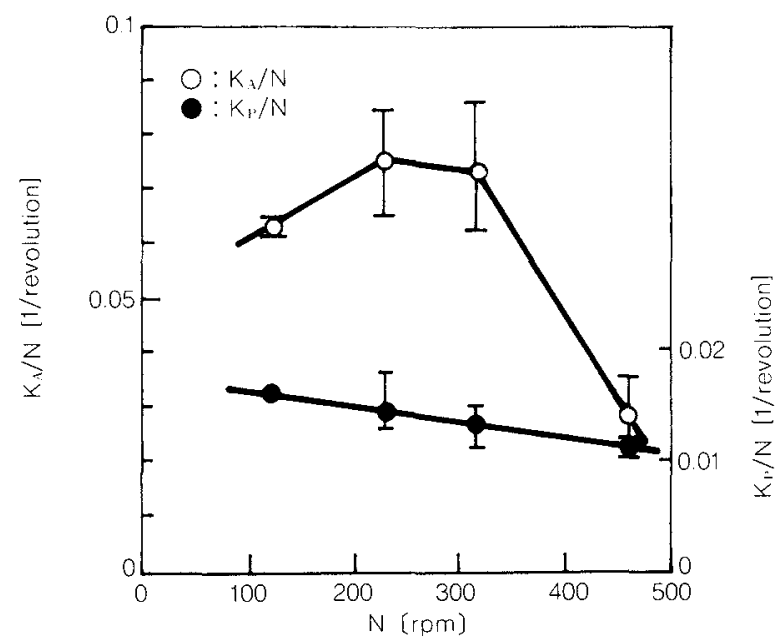

Fig. 6 Effect of the agitator speed on the release rate constant of $\mathrm{ADH}$ and protein 
mum at around $320 \mathrm{rpm}$, and drops sharply at around $460 \mathrm{rpm}$.

These result indicate that $K_{\mathrm{A}}$ and $K_{\mathrm{P}}$ are affected by $N$ differently, and that there is an optimum $N$ level, above which release selectivity decreases as a result of the decreased $K_{\mathrm{A}}$.

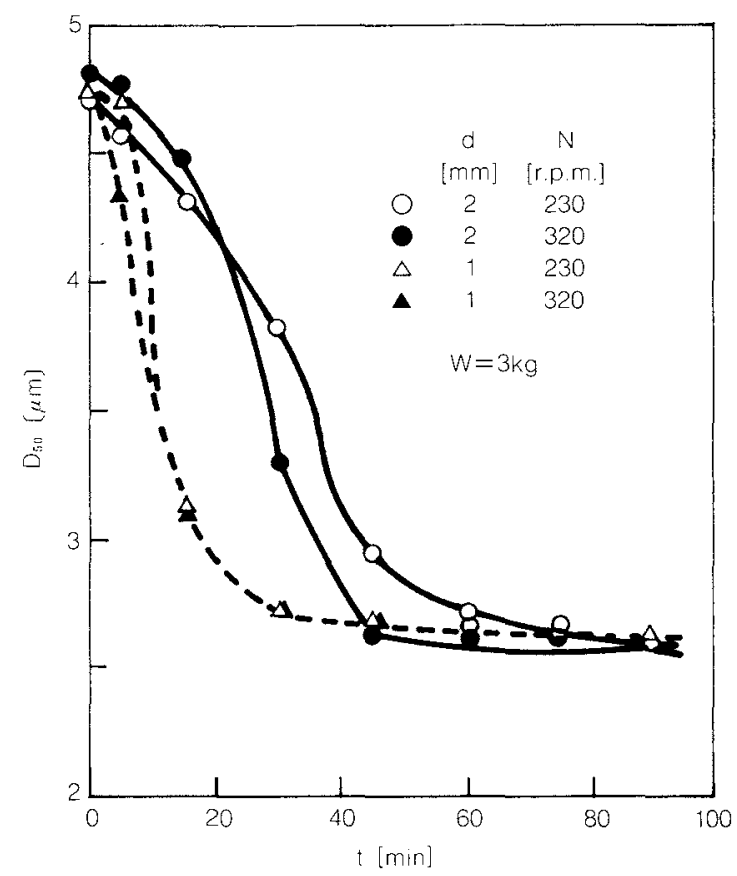

Fig. 7 Relationship between $t$ and $D_{50}$

\section{6 Size of disrupted yeast and release characteristics}

Figure 7 shows the relationship between the disruption time and the $50 \%$ particle size $\left(D_{50}\right)$ of yeast disrupted under varying conditions. The attainable size of disrupted yeast is approximately $2.6 \mu \mathrm{m}$, irrespective of the size of the beads with which it was disrupted, although disruption speed is fastest with $1 \mathrm{~mm}$ beads. Figure 8 presents the SEM photographs of intact and disrupted yeast, where yeast is disrupted using the beads of $1 \mathrm{~mm}$ for $5 \mathrm{~min}$. (b) and $15 \mathrm{~min}$. (c). These photographs indicate that the yeast was not disrupted by the beads into small pieces; instead, the cell walls were partially deformed and disrupted by the beads, thus allowing the intracellular materials (mainly cytoplasm) to escape through the broken cell walls. Therefore, both partially disrupted yeast and the released materials were counted with a Coulter counter.

Figure 9 shows the relationship between the protein release rate $\left(r_{\mathrm{P}}=R_{\mathrm{P}} / R_{m \mathrm{P}}\right)$ and the size

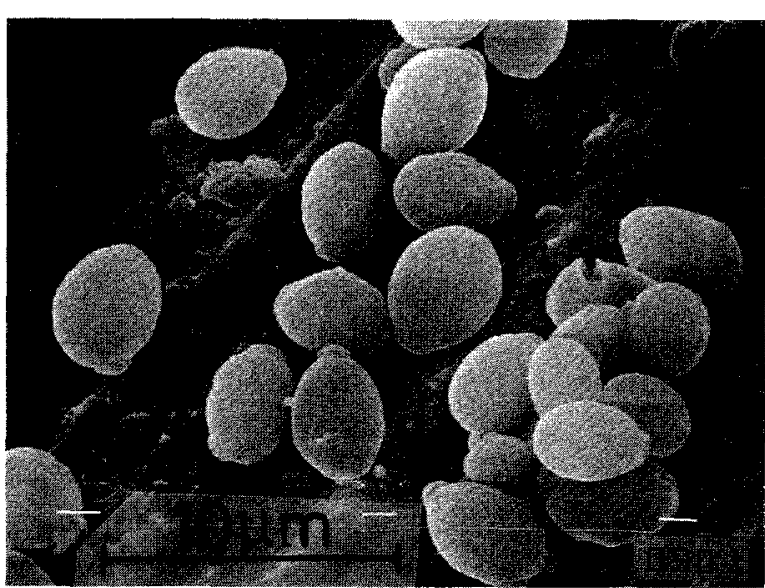

a) $t=0[\mathrm{~min}]$

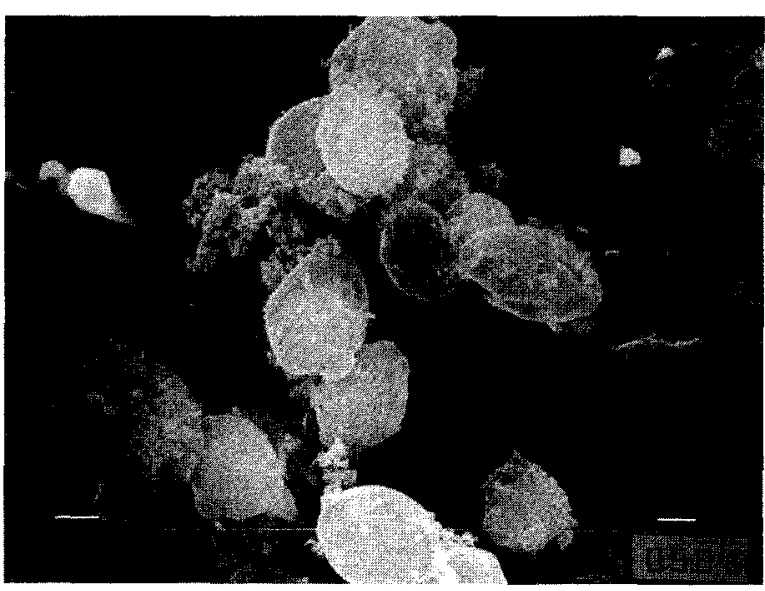

b) $1=5[\mathrm{~min}]$

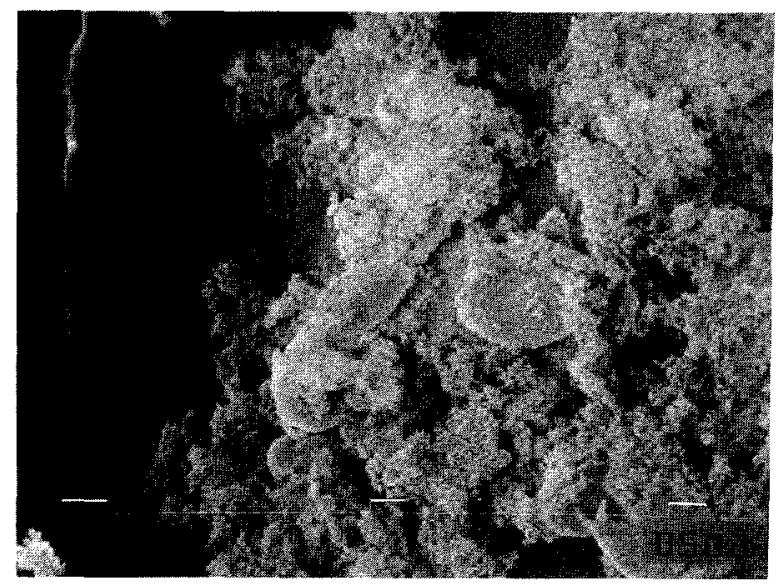

c) $t=15[\mathrm{~min}]$

Fig. 8 SEM photos of disrupted yeast using the glass beads of $d=1$

of disrupted yeast $\left(D_{50}\right)$. As shown, almost $50 \%$ of $R_{m \mathrm{P}}$ was attained by slightly decreasing the yeast size by disruption. In other words, partial disruption can cause the release of intracellular 
release from disrupted yeast can be estimated by measuring the $\lambda$ value. No correlation was observed with $r_{\mathrm{A}}\left(=R_{\mathrm{A}} / R_{m \mathrm{~A}}\right)$.

\section{Conclusions}

Baker's yeast dispersed in pure water was disrupted in batches by using glass beads in order to investigate the release characteristics of ADH, G-6-PDH and proteins. The following results were obtained under the conditions of this study:

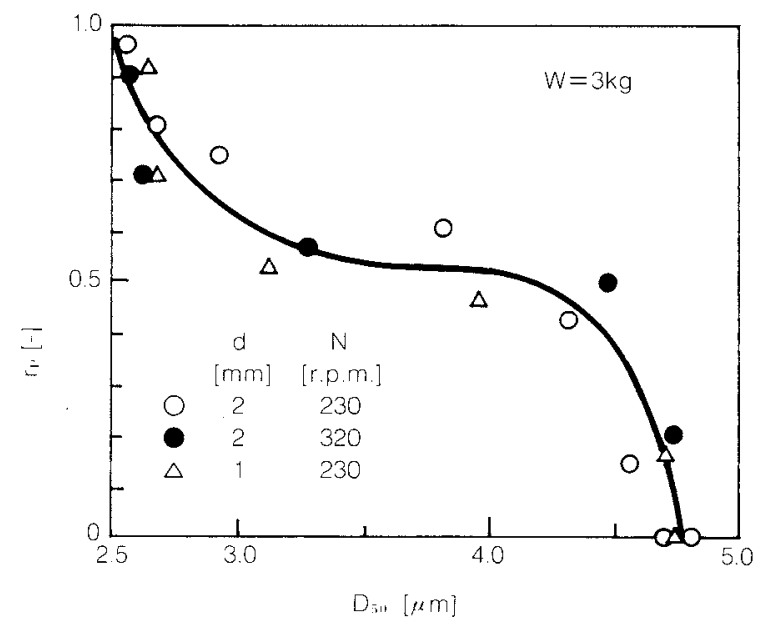

Fig. 9 Relationship between $D_{50}$ and $r_{\mathrm{P}}$

changed with the disruption time with electric conductivity having a higher repeatability. Figure 10 plots $E\left(=\left(\lambda-\lambda_{0}\right) /\left(\lambda \infty-\lambda_{0}\right)\right)$ and $r_{\mathrm{G}} \quad\left(=R_{\mathrm{G}} / R_{m \mathrm{G}}\right)$ against $r_{\mathrm{P}}$, where $\lambda \infty$ and $\lambda_{0}$ are the $\lambda$ value at $t=0$ and $t=90 \mathrm{~min}$, respectively. As shown, $E$ has a strong correlation with $r_{\mathrm{G}}$ and $r_{\mathrm{P}}$ indicating that the extent of

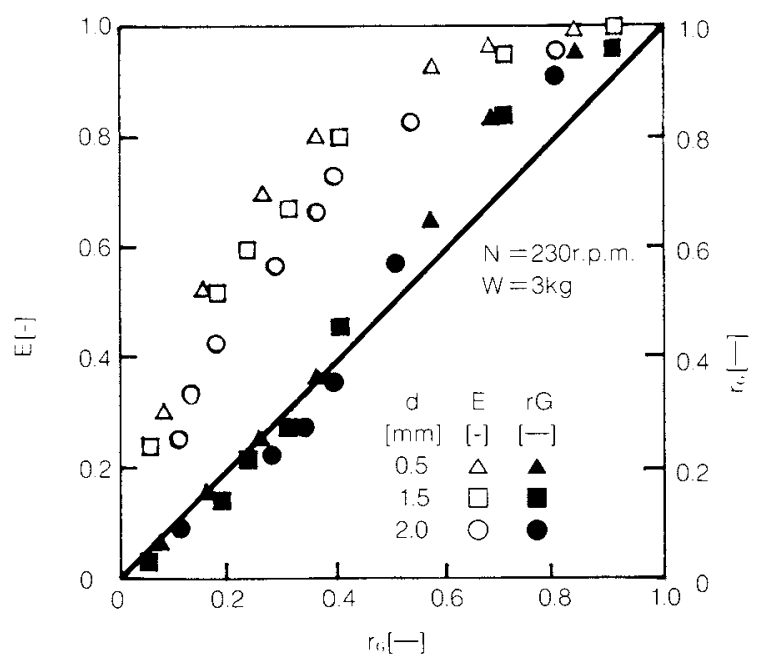

(1) The maximum release rate and selective release characteristics of the materials present in yeast were dependent on the agitator speed on the size and quantity of the beads with which yeast was disrupted. There was an optimum set of operating conditions for each parameter. The indices that represent the release characteristics tended to decrease when the bead size was excessively small or when the agitator speed was excessively high.

(2) The electric conductivity of the disrupted yeast slurry was correlated with the released quantity of G-6-PDH or proteins, allowing us to estimate the released quantities of these materials by measuring the electric conductivity of the slurry.

Nomenclature

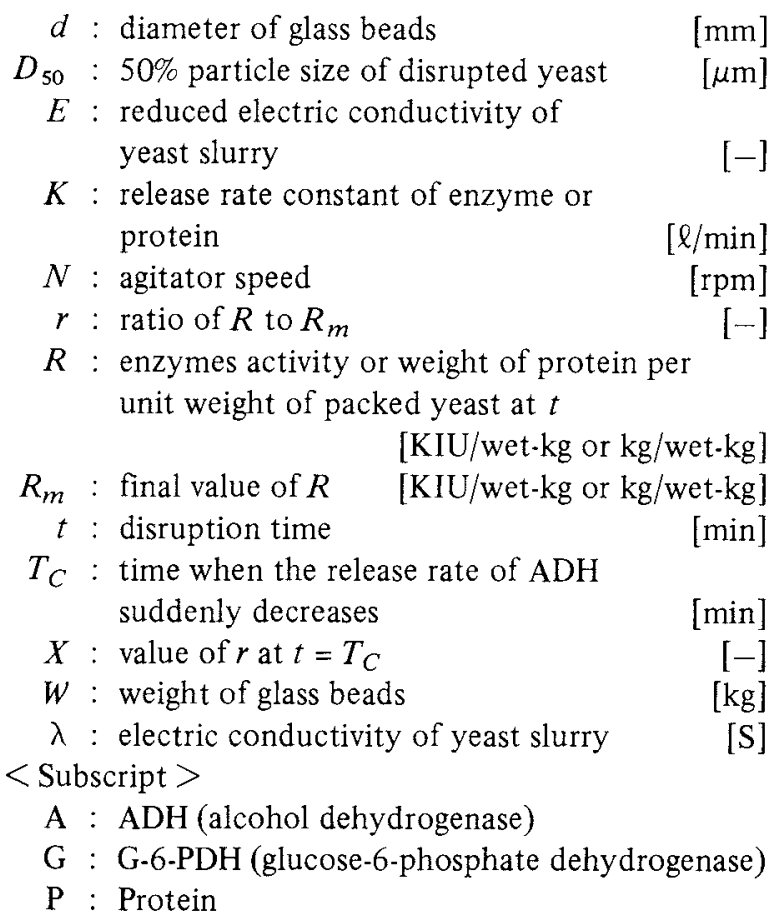

Fig. 10 Correlations among $r_{\mathrm{p}}, r_{\mathrm{G}}$ and $E$ 


\section{References}

1) Wimpenny, J.W.T.: Process Biochemistry, 2, 41 (1967).

2) Matsumoto, K.: J. Soc. Powder Technol., 25, 303 (1988).

3) Hetherrington, P.J., J.M. Follows, P. Dunnill and M.D. Lilly: Trans. Instin. Chem. Engrs., 49, 142 (1971).

4) Schutte, H., K.H. Kroner, H. Hustedt and M.R. Kula: Enzyme Microb, Technol., 5, 143 (1983).

5) Kula, M.-R. and H. Schutte: Biotech, Progress, 3, 31 (1987).

6) Chisti, Y. and M. Moo-young: Enzyme Microb. Technol., 8, 194 (1986).

7) Quirk, A.V. and J.R. Woodrow: Enzyme Microb. Technol., 6, 201 (1984).
8) Asenjo, J.A., B.A. Andrews, J.B. Hunter and S. Lecorre: Process Biochemistry, 59, 158 (1985).

9) Marffy, F. and M.-R. Kula: Biotechnol. Bioeng., 16, 623 (1974).

10) Shetty, J. and J. Kinsella: Biotechnol, Bioeng., 20, 755 (1978).

11) Belter, P.A., E. L. Cussler and W.S. Hu: "Bioseparations", p.89, John Willy \& Sons (1988).

12) Lowry, O.H., N.J. Rosenbrough, A.L. Farr and R.J. Randall: J. Biol. Chem., 193, 265 (1951).

13) Schutte, H. and M.-R. Kula: Ger. Chem. Eng., 9, 149 (1986).

14) Lason, J. L., M. Hoare, C.B. Orsborn, D.J. Doyle and P. Dunnill: Biotechnol. Bioeng., 21,745(1979).

15) Currie, J. A., P. Dunnil and M. D. Lilly: Biotechnol. Bioeng., 14, 725 (1972).

16) Luter, H.: Die Nahrung, 24, 265 (1980). 